\title{
Alterações hematológicas em coelhos infectados experimentalmente pelo Trypanosoma evansi
}

\author{
Hematological changes in rabbits experimentally infected by Trypanosoma evansi
}

\author{
Aleksandro Schafer da Silva' ${ }^{\mathrm{I}}$ Marcio Machado Costa ${ }^{\mathrm{I}}$ \\ Sonia Terezinha dos Anjos Lopes ${ }^{\text {II }}$ Silvia Gonzalez Monteiro ${ }^{\text {III }}$
}

\begin{abstract}
-NOTA-
RESUMO

concentration, hematocrit and mean capsular hemoglobin concentration $(\mathrm{MCHC})$ and an increase in the mean capsular volume (MCV) suggesting a macrocytic hypocrhomic anemia on days 20, 40 and 60. The infected rabbits also presented leucopenia and lymphopenia, as well a significant decrease of neutrophil and monocite counts in comparison to those of the control group.
\end{abstract}

\begin{abstract}
O objetivo deste trabalho foi avaliar as alterações hematológicas em coelhos infectados experimentalmente pelo Trypanosoma evansi. Foram utilizados seis coelhos, machos, divididos em dois grupos, sendo o grupo controle composto de animais não infectados e o grupo teste formado por roedores infectados com T. evansi. Os animais foram mantidos em temperatura ambiente e analisados por 120 dias, através de cinco coletas de sangue nos dias 1, 20, 40,60 e 120. As alterações hematológicas foram observadas na segunda e terceira coletas de sangue. Nos animais com parasitemia, foi observada uma redução no número de hemácias, de concentração de hemoglobina no hematócrito, na concentração de hemoglobina corpuscular média (CHCM), $e$ um aumento do volume corpuscular médio (VCM), sugerindo uma anemia macrocítica hipocrômica no período de 20, 40 e 60 dias. Os coelhos infectados também apresentaram leucopenia e linfopenia, além de uma redução significativa no número de neutrófilos e monócitos, quando comparados com os animais do grupo controle.
\end{abstract}

Palavras-chave: anemia, parasitemia, hematologia, protozoário.

\section{ABSTRACT}

The present paper was aimed at evaluating hematological changes in rabbits experimentally infected by Trypanosoma evansi. Six male rabbits divided in to two groups were used, being the control group composed of non-infected animals and the test group composed of animals infected by $\boldsymbol{T}$. evansi. The animals were kept at room temperature and were analyzed during 120 days, by blood collections on days 1, 20, 40, 60 and 120. Hematological changes were observed in the second and third blood collections and the animals with parasitism had a decrease in blood cells, hemoglobin
Key words: anemia, parasitem, hematology, protozoan.

Trypanosoma evansi é um protozoário flagelado e digenético transmitido por insetos hematófagos para mamíferos durante o repasto sanguíneo (SILVA et al., 2002). No Brasil, é muito freqüente na região do Pantanal Matogrossense, onde são encontrados em reservatórios silvestres, em capivaras, quatis e pequenos roedores e, em animais domésticos, como cães, eqüinos e suínos (SILVA et al., 2002; HERRERA et al., 2004). Na Índia, foi registrado recentemente o primeiro caso de infecção pelo protozoário em seres humanos (JOSHI et al., 2005).

Em camelos, cães e roedores a infecção por T. evansi leva a alterações, como anemia, declínio acentuado do hematócrito e do teor de hemoglobina, leucopenia, neutropenia e hiperproteinemia, além de redução no número de linfócitos e basofilos (HOLWIL, 1965; JATKAR \& PUROHIT, 1971; AQUINO et al., 2002). Devido ao grande número de hospedeiros e à importância do T. evansi na pecuária brasileira, este estudo teve como objetivo avaliar as alterações

${ }^{\mathrm{I} C u r s o}$ de Medicina Veterinária, Universidade Federal de Santa Maria (UFSM), Santa Maria, RS, Brasil.

"Departamento de Pequenos Animais, UFSM, Santa Maria, RS, Brasil.

IIIDepartamento de Microbiologia e Parasitologia, UFSM. Faixa de Camobi, Km 9, Campus Universitário, 97105-900, Prédio 20, Sala 4232, Fax (55)3220-8958, Santa Maria, RS, Brasil. E-mail: sgmonteiro@uol.com.br. Autor para correspondência. 
hematológicas em coelhos infectados experimentalmente com o protozoário, a fim de conhecer os efeitos da parasitemia em animais de laboratório, nos quais se realizam os primeiros testes medicamentosos.

Foram utilizados seis coelhos Nova Zelândia brancos, machos, com idade entre 2 e 6 meses. Eles foram divididos em dois grupos iguais, sendo que os coelhos do grupo A eram sadios, e foram utilizados como grupo controle e os do grupo B cada um foi inoculado experimentalmente com $0,5 \mathrm{~mL}$ de sangue, contendo $10^{6}$ tripomastigotas pela via intraperitoneal. Os animais foram mantidos em gaiolas individuais, alimentados com ração comercial e tratados com antihelmíntico (piperazina) 15 dias antes de iniciar o experimento. $\mathrm{O}$ isolado de T. evansi proveniente de cães infectados naturalmente no município de Uruguaiana, Rio Grande do Sul (COLPO et al., 2005) foi mantido em laboratório sob cultura viva em ratos Wistar para utilização neste experimento.

O controle da parasitemia foi realizado através da análise de esfregaços sangüíneos diários, coletados da orelha de cada animal. Após a desinfecção da região auricular com algodão embebido em álcool iodado, foi feita a perfuração da pele com agulha hipodérmica estéril, permitindo a coleta de uma gota de sangue sobre lâmina de vidro para a realização do esfregaço sanguíneo. Após a secagem, os esfregaços foram corados com Panóptico Rápido ${ }^{\circledR}$ e levados ao microscópio óptico para avaliar a presença dos protozoários na circulação em aumento de 1000 vezes (SILVA et al., 2006).

As amostras de sangue para hematologia foram colhidas por punção cardíaca, com a utilização de seringas de $5 \mathrm{ml}$ e agulhas $25 \times 7$, armazenadas em tubos com sal sódico do ácido etilenodiaminotetracético (EDTA-Na) a 10\%. Foram feitas cinco coletas no período de 120 dias, sendo estas realizadas dias 1, 20, 40,60 e 120 após a infecção.

Os parâmetros hematológicos analisados neste trabalho foram o número de hemácias, o hematócrito (Hct), o volume corpuscular médio (VCM), a concentração de hemoglobina $(\mathrm{Hb})$, a concentração de hemoglobina corpuscular média (CHCM), a concentração de proteínas plasmáticas e o número de leucócitos totais, de linfócitos, de neutrófilos segmentados e de monócitos. Os esfregaços sanguíneos foram corados com Panótico Rápido para a contagem diferencial e a avaliação citológica. As contagens de hemácias e de leucócitos totais e a determinação da concentração de hemoglobina foram realizadas em aparelho de contagem celular eletrônico $\left(\mathrm{CELM}^{\circledR}\right.$ - mod. CC 530). As determinações do volume globular e da contagem diferencial dos leucócitos foram efetuadas de acordo com a técnica descrita por FELDMAN et al. (2000). A interpretação dos resultados foi realizada segundo BUSH (2004) e LOPEZ \& CUNHA (2002). A análise estatística dos dados foi feita através da análise de variância (ANOVA), seguida da aplicação do teste de TUKEY para comparação entre as médias (SILVA\&AZEVEDO, 2002).

A redução no número de hemácias, da concentração de hemoglogina e do hematócrito sugerem anemia. Com o aumento do VCM e a redução da CHCM, esta anemia pode ser classificada como macrocítica hipocrômica, característica de uma anemia hemolítica. Estas alterações foram observadas na segunda e na terceira coletas após a inoculação dos coelhos com o T. evansi, isto é, entre os 20 e 40 dias após a infecção (Tabela 1). Os animais avaliados não apresentaram alterações no hemograma após 60 dias de inoculação do parasito e o protozoário desapareceu da circulação em 82 dias após o início do experimento. Semelhante a este estudo, AQUINO et al. (2002) observaram declínio acentuado do hematócrito e do teor de hemoglobina em cães e JATKAR \& PUROHIT (1971) encontraram anemia macrocítica com presença de reticulócitos, normoblastos e esferócitos, acompanhada de hiperplasia da medula óssea de camelos infectados por T. evansi.

De acordo com a literatura, a anemia é uma característica comum das infecções por tripanossomas, sendo de natureza hemolítica em resultado à eritrofagocitose no baço, no fígado, nos pulmões, nos linfonodos, na medula óssea e na circulação devido à ação traumática direta dos protozoários sobre as hemácias que aumentam a fragilidade celular. Além disso há o aspecto imunológico envolvido, uma vez que os antígenos de tripanossomas se aderem à membrana das hemácias, tornando-as susceptíveis à fagocitose, mecanismo este que possivelmente tenha ocorrido neste estudo, em que os animais apresentaram anemia (HOLWIL, 1965; HERBERT \& INGLIS, 1973; JAIN, 1993).

Neste estudo os coelhos apresentaram anemia macrocítica hipocrômica apesar da baixa parasitemia no decorrer do experimento. No entanto, BRANDÃO et al. (2002), ao analisarem um cão naturalmente infectado por T. evansi com parasitemia de 15 a 20 tripomastigotas por campo a $500 \mathrm{x}$ de aumento, observaram anemia arregenerativa. Estas alterações, possivelmente estão relacionadas aos diferentes hospedeiros do parasito, sendo que UCHE et al. (1992) afirma que os coelhos são resistentes à infecção.

Observou-se um aumento na concentração de proteínas plasmáticas no período de anemia (Tabela 1), possivelmente devido à estimulação antigênica (BUSH, 
Tabela 1 - Medias e desvio padrão do eritrograma de coelhos infectados experimentalmente com Trypanosoma evansi.

\begin{tabular}{|c|c|c|c|}
\hline Hemograma & Dias da coleta & Coelhos controle & $\begin{array}{c}\text { Coelhos parasitados por } \boldsymbol{T} . \\
\text { evansi }\end{array}$ \\
\hline \multirow{4}{*}{$\begin{array}{l}\text { Hemácias } \\
\left(\times 10^{6} / \mathrm{mm}^{3}\right)\end{array}$} & 1 & $4,96^{\mathrm{a}}( \pm 0,22)$ & $5,14^{\mathrm{a}}( \pm 0,56)$ \\
\hline & 20 & $5,18^{\mathrm{a}}( \pm 0,41)$ & $3,82^{\mathrm{b}}( \pm 0,71)$ \\
\hline & 40 & $5,28^{\mathrm{a}}( \pm 0,12)$ & $3,83^{\mathrm{b}}( \pm 0,25)$ \\
\hline & 60 & $5,44^{\mathrm{a}}( \pm 0,65)$ & $4,82^{\mathrm{a}}( \pm 0,49)$ \\
\hline \multirow{6}{*}{$\begin{array}{l}\text { Hemoglobina } \\
(\mathrm{mg} / \mathrm{dl})\end{array}$} & 120 & $5,58^{\mathrm{a}}( \pm 1,1)$ & $4,94^{\mathrm{a}}( \pm 0,32)$ \\
\hline & 1 & $12,30^{\mathrm{a}}( \pm 1,1)$ & $11,26^{\mathrm{a}}( \pm 0,5)$ \\
\hline & 20 & $11,43^{\mathrm{a}}( \pm 1,3)$ & $9,00^{\mathrm{b}}( \pm 0,9)$ \\
\hline & 40 & $12,50^{\mathrm{a}}( \pm 0,8)$ & $9,20^{\mathrm{b}}( \pm 0,3)$ \\
\hline & 60 & $11,86^{\mathrm{a}}( \pm 0,2)$ & $11,26^{\mathrm{a}}( \pm 0,5)$ \\
\hline & 120 & $11,6^{\mathrm{a}}( \pm 0,5)$ & $11,00^{\mathrm{a}}( \pm 0,9)$ \\
\hline \multirow{4}{*}{$\begin{array}{l}\text { Hematócrito } \\
(\%)\end{array}$} & 1 & $35^{\mathrm{a}}( \pm 4,1)$ & $37^{a}( \pm 4)$ \\
\hline & 20 & $39^{\mathrm{a}}( \pm 5)$ & $31^{\mathrm{b}}( \pm 1,5)$ \\
\hline & 40 & $39^{\mathrm{a}}( \pm 2,2)$ & $30^{\mathrm{b}}( \pm 2)$ \\
\hline & 60 & $41^{\mathrm{a}}( \pm 3,6)$ & $37^{\mathrm{a}}( \pm 3)$ \\
\hline \multirow{6}{*}{$\begin{array}{l}\text { Proteínas } \\
\text { Plasmáticas (g/dl) }\end{array}$} & 120 & $39^{\mathrm{a}}( \pm 4)$ & $36^{\mathrm{a}}( \pm 2,8)$ \\
\hline & 1 & $7,16^{\mathrm{a}}( \pm 1,1)$ & $7,43^{\mathrm{a}}( \pm 1,2)$ \\
\hline & 20 & $7,23^{\mathrm{a}}( \pm 1,6)$ & $9,00^{\mathrm{b}}( \pm 0,4)$ \\
\hline & 40 & $6.90^{\mathrm{a}}( \pm 0,2)$ & $8,80^{\mathrm{b}}( \pm 0,2)$ \\
\hline & 60 & $6,70^{\mathrm{a}}( \pm 0,6)$ & $7.60^{\mathrm{a}}( \pm 0,8)$ \\
\hline & 120 & $6.90^{\mathrm{a}}( \pm 0,3)$ & $8,80^{\mathrm{b}}( \pm 0,7)$ \\
\hline \multirow{5}{*}{ VCM (fl) } & 1 & $71,88^{\mathrm{a}}( \pm 2,4)$ & $73,68^{\mathrm{a}}( \pm 3,2)$ \\
\hline & 20 & $70,11^{\mathrm{a}}( \pm 3,1)$ & $86,56^{\mathrm{b}}( \pm 2,0)$ \\
\hline & 40 & $73,68^{\mathrm{a}}( \pm 0,9)$ & $81,00^{\mathrm{b}}( \pm 1,1)$ \\
\hline & 60 & $70,05^{\mathrm{a}}( \pm 2,1)$ & $77,00^{\mathrm{a}}( \pm 3,3)$ \\
\hline & 120 & $72,30^{\mathrm{a}}( \pm 1,2)$ & $74,56^{\mathrm{a}}( \pm 2,6)$ \\
\hline \multirow{5}{*}{ CHCM (\%) } & 1 & $30,88^{\mathrm{a}}( \pm 1,5)$ & $32,28^{\mathrm{a}}( \pm 1,3)$ \\
\hline & 20 & $32,28^{\mathrm{a}}( \pm 2,1)$ & $28,97^{\mathrm{a}}( \pm 0,5)$ \\
\hline & 40 & $33,42^{\mathrm{a}}( \pm 1,5)$ & $29,68^{\mathrm{a}}( \pm 0,6)$ \\
\hline & 60 & $33,25^{\mathrm{a}}( \pm 1,9)$ & $30,00^{\mathrm{a}}( \pm 1,0)$ \\
\hline & 120 & $31,26^{\mathrm{a}}( \pm 1,2)$ & $31,14^{\mathrm{a}}( \pm 1,1)$ \\
\hline
\end{tabular}

Obs: Médias seguidas por letras iguais na mesma linha não diferem estatisticamente entre si a 5\% de probabilidade pelo teste de TUKEY.

2004). Resultado semelhante foi reportado por THOMAS (2000) em infecções crônicas, em que o aumento na produção de gamaglobulinas refletiu em aumento na concentração das proteínas plasmáticas.

No leucograma, observou-se leucopenia e linfopenia (Tabela 2). A leucopenia, encontrada aos 20, 40 e 60 dias pós-infecção se deve à linfopenia e à diminuição dos monócitos, embora os valores correspondentes tenham se mantido dentro da normalidade. É possível que a linfopenia esteja relacionada ao confinamento temporário dos linfócitos no baço e/ou não linfonodos em resposta aos antígenos do protozoário ou então decorra da destruição dos linfócitos pelo agente infeccioso, como discutido em casos de leishmanione (BUSH, 2004).

Conforme JATKAR \& PUROHIT (1971) e BRANDÃO et al. (2002), cães e camelos podem apresentar alterações semelhantes às ocorridas em coelhos neste estudo como, leucopenia, e linfopenia, e diminuição dos valores de leucócitos totais, quando infectados com T. evansi. Entretanto, cavalos, em sua maioria, desenvolvem apenas anemia (SILVA et al., 1995).

Verificou-se que os animais parasitados tinham o número de monócitos inferior ao do grupo controle, sendo observada diferença estatística entre os dois grupos. No entanto, os valores apresentaramse dentro dos parâmetros da normalidade, segundo FELDMAN et al. (2000). AQUINO et al. (2002) avaliaram cães infectados pelo T. evansi e obtiveram uma redução semelhante à deste estudo no número de neutrófilos. Porém, HOLWIL (1965) observou um aumento no número de neutrófilos e monócitos em cães e cavalos infectados por T. evansi, alterações não ocorridas neste estudo. JATKAR \& PUROHIT (1971) observaram um aumento no número de eosinófilos em camelos 
Tabela 2 - Médias e desvio padrão do leucograma de coelhos infectados experimentalmente com Trypanosoma evansi.

\begin{tabular}{|c|c|c|c|}
\hline Leucograma & Dias de coleta & Coelhos controle & $\begin{array}{c}\text { Coelhos parasitados por } \boldsymbol{T} . \\
\text { evansi }\end{array}$ \\
\hline \multirow{5}{*}{ Leucócitos $\left(/ \mathrm{mm}^{3}\right)$} & 1 & $87,33^{\mathrm{a}}( \pm 254,2)$ & $8300^{\mathrm{a}}( \pm 120,7)$ \\
\hline & 20 & $8867^{\mathrm{a}}( \pm 568,9)$ & $7133^{\mathrm{b}}( \pm 333,3)$ \\
\hline & 40 & $8033^{\mathrm{a}}( \pm 123,7)$ & $3400^{\mathrm{b}}( \pm 214,4)$ \\
\hline & 60 & $8500^{\mathrm{a}}( \pm 780,5)$ & $6133^{\mathrm{b}}( \pm 140,4)$ \\
\hline & 120 & $8200^{\mathrm{a}}( \pm 200,1)$ & $7533^{\mathrm{a}}( \pm 94,3)$ \\
\hline \multirow{5}{*}{ Neutrófilos $(/ \mu \mathrm{L})$} & 1 & $2803^{\mathrm{a}}( \pm 854,6)$ & $3173^{\mathrm{a}}( \pm 423,8)$ \\
\hline & 20 & $3080^{\mathrm{a}}( \pm 244,7)$ & $2470^{\mathrm{a}}( \pm 250,1)$ \\
\hline & 40 & $3695^{\mathrm{a}}( \pm 564,8)$ & $2755^{\mathrm{a}}( \pm 205)$ \\
\hline & 60 & $4079^{\mathrm{a}}( \pm 981,5)$ & $2655^{\mathrm{a}}( \pm 455,6)$ \\
\hline & 120 & $3156^{\mathrm{a}}( \pm 54,2)$ & $3731^{\mathrm{a}}( \pm 324,3)$ \\
\hline \multirow{5}{*}{ Linfócitos $(/ \mu \mathrm{L})$} & 1 & $3684^{\mathrm{a}}( \pm 156,3)$ & $3908^{\mathrm{a}}( \pm 782,7)$ \\
\hline & 20 & $3690^{\mathrm{a}}( \pm 624,1)$ & $1319^{\mathrm{b}}( \pm 450,7)$ \\
\hline & 40 & $4137^{\mathrm{a}}( \pm 233,9)$ & $1718^{\mathrm{b}}( \pm 170,1)$ \\
\hline & 60 & $3786^{\mathrm{a}}( \pm 420,8)$ & $2959^{\mathrm{b}}( \pm 684,2)$ \\
\hline & 120 & $3710^{\mathrm{a}}( \pm 110)$ & $3818^{\mathrm{a}}( \pm 266,8)$ \\
\hline \multirow{5}{*}{ Monócitos $(/ \mu \mathrm{L})$} & 1 & $406^{\mathrm{a}}( \pm 52,2)$ & $229^{\mathrm{a}}( \pm 65,5)$ \\
\hline & 20 & $440^{\mathrm{a}}( \pm 40,9)$ & $85^{\mathrm{b}}( \pm 21,4)$ \\
\hline & 40 & $378^{\mathrm{a}}( \pm 45,1)$ & $154^{\mathrm{b}}( \pm 34,3)$ \\
\hline & 60 & $203^{\mathrm{a}}( \pm 33,7)$ & $197^{\mathrm{a}}( \pm 38,5)$ \\
\hline & 120 & $380^{\mathrm{a}}( \pm 25)$ & $244^{\mathrm{a}}( \pm 56,2)$ \\
\hline \multirow{5}{*}{ Eosinofilos $(/ \mu \mathrm{L})$} & 1 & $20^{\mathrm{a}}( \pm 11,5)$ & $10^{\mathrm{a}}( \pm 5,7)$ \\
\hline & 20 & $50^{\mathrm{a}}( \pm 28,8)$ & $60^{\mathrm{a}}( \pm 17,3)$ \\
\hline & 40 & $0.0^{\mathrm{a}}( \pm 0)$ & $100^{\mathrm{a}}( \pm 5,7)$ \\
\hline & 60 & $30^{\mathrm{a}}( \pm 17,3)$ & $60^{\mathrm{a}}( \pm 20)$ \\
\hline & 120 & $10^{\mathrm{a}}( \pm 5,7)$ & $64^{\mathrm{a}}( \pm 8,6)$ \\
\hline
\end{tabular}

Obs: Médias seguidas por letras iguais na mesma linha não diferem estatisticamente entre si a 5\% de probabilidade do teste de TUKEY

parasitados pelo T. evansi, dado este semelhante ao deste estudo, em coelhos do grupo B, embora estes valores estivessem dentro da faixa de normalidade (FELDMAN et al., 2000). Coelhos infectados experimentalmente com T. evansi apresentam anemia macrocítica hipocrômica, leucopenia e linfopenia. As alterações hematológicas são detectáveis aos 20, 40 e 60 dias após a infecção. O protozoário desapareceu da corrente sanguínea dos animais após 82 dias, mesmo período que os valores hematológicos voltaram à normalidade, o que sugere que os coelhos são refratários ao parasito.

\section{REFERÊNCIAS}

AQUINO, L.P.C.T. et al. Aspectos hematológicos, bioquímicos e anatomopatológicos da infecção de Trypanosoma evansi em cães. Arquivo Brasileiro de Medicina veterinária e Zootecnia, v.54, n.1, p.8-18, 2002.

BRANDÃO, L.P. et al. Infecção Natural pelo Trypanosoma evansi em cão - Relato de caso. Clínica Veterinária, Ano VII, n.6, p.23-26, 2002.

BUSH, B.M. Interpretação de resultados laboratoriais para clínicos de pequenos animais. São Paulo: Roca, 2004. 376p.
COLPO, C.B. et al. Infecção Natural por Trypanosoma evansi em cão no Rio Grande do Sul. Ciência Rural, v.35, n.3, p.717-719, 2005 .

FELDMAN, B.F. et al. Veterinary hematology. Philadelphia: Williams \& Wilkins, 2000. 1344p.

HERRERA, H.M. et al. Enzootiology of Trypanosoma evansi in Pantanal, Brazil. Veterinary Parasitology, v.125, n.3-4, p.263-275, 2004 .

HERBERT, C.N.; INGLIS, M.D. Immunization of mice against Trypanosoma brucei infections by administration of released antigens absorbed to erythrocytes. Transactions of the Royal Society Tropical Medicine and Hygiene, v.67, p.268-272, 1973.

HOLWIL, M.G. Deformation of erythrocytes by trypanosomes. Experimental Cellular Research, v.37, p.306-311, 1965.

JAIN, N.C. Essentials of veterinary hematology. Philadelphia: Lea \& Fabinger, 1993. 417p.

JATKAR, P.R.; PUROHIT. M.S. Pathogenesis of anaemia in Trypanosoma evansi infection. I. Haematology. Indian Veterinary Journal, v.48 n.3, p.239-244, 1971. 
JOSHI, P.P. et al. Human Trypanosomosis caused by Trypanosoma evansi in India: the first case report. American Journal of Tropical Medicine and Hygiene, v.73, n.3, p.491-495, 2005.

LOPES, S.T.A.; CUNHA, C.M.S. Patologia clínica veterinária. Santa Maria: UFSM, 2002. 125p.

SILVA, R.A.M.S. et al. Pathogenesis of Trypanosoma evansi Infection in dogs and horses: hematological and clinical aspects. Ciência Rural, v.25, p.233-238, 1995.

SILVA, F.A.S.; AZEVEDO, C.A.V. Versão do programa computacional Assistat para o sistema operacional Windows. Revista Brasileira de Produtos Agroindustriais, v. 4, n. 1, p. 71-78, 2002.
SILVA, R.A.M.S. et al. Trypanosoma evansi e Trypanosoma vivax - biologia, diagnóstico e controle. 2002. Capturada em 15 de jan. 2005. Online. Disponível na Internet: http:// www.cpap.embrapa.br/publicacoes/online/Livro015.

SILVA, A.S. et al. Métodos de contenção e confecção de esfregaço sanguíneo para pesquisa de hemoparasitas em ratos e camundongos. Revista da Faculdade de Zootecnia, Veterinária e Agronomia, v.14, n.2, p.26-29, 2006.

THOMAS, J.S. Overview of plasma proteins. In: FELDMAN, B.F. et al. Veterinary Hematology. Philadelphia: Lippincott. Cap. 134, p. 891-898, 2000.

UCHE, U.E. et al. Antibody patterns in rabbits showing different levels of susceptibility to an experimental Trypanosoma evansi infection. Acta Tropica, v.52, p.139-147, 1992. 